\title{
Farklı yumuşak astar materyallerinin Candida albicans biyofilm formasyonu açısından değerlendirilmesi
}

\author{
Duygu Karakış, ${ }^{1 *}$ Canan Akay, ${ }^{1}$ Demet Erdönmez, ${ }^{2}$ \\ Arife Doğan ${ }^{1}$ \\ ${ }^{1}$ Protetik Diş Tedavisi Anabilim Dalı, Gazi Üniversitesi \\ Diş Hekimliği Fakültesi, ${ }^{2}$ Biyoteknoloji Anabilim Dalı, \\ Biyoloji Bölümü, Hacettepe Üniversitesi Fen Fakültesi, \\ Ankara, Türkiye
}

\section{ÖZet}

AmAÇ: Bu çalışmada iki farklı yüzey yapısına göre hazırlanan yumuşak astar materyallerinde Candida albicans biyofilm oluşumunun değerlendirilmesi amaçlanmiştır.

GEREÇ VE YöNTEM: Dört yumuşak astar materyali (Molloplast B, Permafleks, Elite-Soft, Ufi Gel P) cam veya alçı yüzeyler üzerinde hazırlandı $(5 \times 5 \times 2 \mathrm{~mm} ; \mathrm{n}=5)$. Tüm örneklerin yüzey pürüzlülükleri ve temas açıları ölçüldü. Candida albicans ATCC 10231 Sabouraud dextrose besiyeri (SDB) içerisinde $37{ }^{\circ} C^{\prime}$ de 24 saat süresince çoğaltıldı. Ardından, biyofilm oluşumu için örnekler polistren kuyucuklarda, önceden elde edilen Candida albicans kültürü ve taze SDB ilavesiyle $37{ }^{\circ} \mathrm{C}$ 'de 48 saat süresince enkübe edildi. Örnekler $\% 0.1$ kristal viyole solüsyonu ile boyanarak $65^{\circ} \mathrm{C}$ 'de kurumaya bırakıldı. Biyofilm oluşumu spektrofotometrik yöntemle incelendi. Test edilen materyallerin yüzey pürüzlülüğü, temas açıları ve biyofilm formasyonlarının karşılaştırılması oneway ANOVA ve Tukey testi ile yapıldı. Cam veya alçı yüzeylerde hazırlanan örneklerin yüzey pürüzlülüğü, temas açıları ve biyofilm oluşumu arasındaki korelasyon Pearson korelasyon analizi ile incelendi.

BULGULAR: Alçı yüzeyinde hazırlanan örneklerde yüzey pürüzlülüğü, temas açısı ve biyofilm oluşumu, cam üzerinde hazırlananlara göre istatistiksel olarak daha fazla bulundu ( $p<0.05)$. Alçı yüzeyde hazırlanan yumuşak astar materyallerinde biyofilm oluşumu, en fazla Ufi Gel P ve en az Molloplast B örneklerinde bulundu. Cam yüzeyde hazırlanan örneklerde ise en fazla biyofilm oluşumu Ufi Gel P'de bulundu. Candida albicans bağlanması ile hiçbir yumuşak astar materyalinin yüzey özellikleri (yüzey pürüzlülüğü, temas açısı) arasında korelasyon bulunmadı $(p>0.05)$.

Makale gönderiliş tarihi: 09 Haziran 2014; Yayına kabul tarihi: 05 Eylül 2014 *iletişim: Duygu Karakış, Protetik Diş Tedavisi Anabilim Dalı, Gazi Üniversitesi Diş Hekimliği Fakültesi, 82. sokak, 06510, Emek, Ankara, Türkiye;

e-posta: dtduygukc@ hotmail.com
Sonuç: Test edilen yumuşak astar materyalleri, yüzey topografik özellikleri açısından benzer olsalar da farklı miktarlarda Candida albicans biyofilm oluşumu gösterdiler. Düz yüzeylerin biyofilm oluşumunu azalttığı gözlendi.

AnAhtAR Kelimeler: Biyofilm; Kandida albikans; polidimetilsiloksanlar

Kaynak Göstermek İçin: Karakış D, Akay C, Erdönmez D, Doğan A. Farklı yumuşak astar materyallerinin Candida albicans biyofilm formasyonu açısından değerlendirilmesi.

Acta Odontol Turc 2015;32(1):19-25

YAYıN HAKKI: (c) 2015 Karakış ve ark. Bu eserin yayın hakkı Creative Commons Attribution License ile ruhsatlandırılmıştır. Sınırsız kullanım, dağıtım ve her türlü ortamda çoğaltım, yazarlar ve kaynağın belirtilmesi kaydıyla serbesttir.

[Abstract in English is at the end of the manuscript]

\section{Giriş}

Akrilik rezinler, özellikle polimetil metakrilat (PMMA), diş hekimliğinde uzun süredir protez kaide rezini olarak yaygın şekilde kullanılmaktadır. Yeterli mekanik ve fiziksel özelliklerinin yanı sıra uygulama ve tamir kolaylığı, renklendirici ilavesi ile estetik görünüm ve düşük maliyet gibi pek çok avantaja sahiptir. Ancak, özellikle aşırı duyarlı mukoza vakalarında, hastalar böyle sert kaide plağını tolere edemeyebilmektedirler; hastaların yeni protezlerine uyum sağlamalarında yumuşak astar materyalleri önemli yardımcı unsurlardır. ${ }^{1-4}$

Yumuşak astar materyalleri, protetik apareyle alttaki dokulara geçirilen kuvvetleri azaltmak üzere sert protez kaidesi ve dokular arasında bir yastık benzeri işlev görür. Bu materyaller, fibromukoz membranla temas ettiklerinde şok emici gibi davranır ve okluzal yüklerin daha homojen dağılımını sağlayarak, keskin ve/veya oldukça rezorbe alveolar kretler ve duyarlı mukozalı hastalarda rahatsızlığı azaltırlar., ${ }^{1,5,6}$

Mekanik özellikler ve klinik davranış yönünden farklılık gösteren çok sayıda yumuşak astar materyali mevcuttur. Bunlar arasında en yaygın kullanılanlar, plastisize akrilik ve silikon elastomerlerdir. Her iki tipin oda ısısında veya ısıyla polimerize olanları mevcuttur; her birinin 
plastisizer, çapraz bağlantı ajanı, katalist ve doldurucu yüzdeleri farklıdır. ${ }^{2,7,8}$ Bunlar arasında, özellikle uzun süreli başarılı uygulamaları nedeniyle silikon elastomerler öne çıkmaktadır. ${ }^{5}$

Silikon astar materyaller polidimetil siloksan (PDMS) polimerlerden oluşur ve uygun kıvam sağlamak için doldurucu eklenir, plastikleştirici akriliklerden farklı olarak sızabilir plastikleştirici içermezler, dolayısıyla yumuşaklıklarını uzun süre koruyabilirler.3,9,10 Mükemmel fleksibilite, sağlamlık ve yüksek termal ve oksidatif stabiliteleri gibi istenen özelliklere karşın, PMMA ile güçlü adezyon sağlayabilen reaktif yüzey gruplarına sahip değildir. ${ }^{11}$ Ayrıca, göreceli olarak yüksek miktarda düşük moleküler ağırlıklı bileşenleri de PDMS'nin protez kaide rezinine adezyonunu etkiler. Bu zayıf ara yüz bağlantısı bakteriyel çoğalma, plak ve diş taşı oluşumu gibi bazı sorunları tetikler. ${ }^{9}$

Yumuşak astar materyalleri mikrobiyal kolonizasyona geleneksel PMMA'dan daha fazla yatkındır. Yüzey yapıları, fiziksel/kimyasal afiniteleri ve antimikrobiyal aktivite eksikliğinden dolayı oral mikroorganizmalarla etkileşirler. ${ }^{12}$ Mikroorganizmalar, materyalin biyo-bozunmasına yol açarak astara yapışabilir ve birikebilirler. ${ }^{13,14}$ Böyle bozunma protez/astarın kaldırılması veya yeniden yapımını gerektirebilir. ${ }^{15}$ Ayrıca, protez, umulmadık enfeksiyona yol açar tarzda mikroorganizmaların yutulduğu veya aspire edilebildiği bir rezervuar gibi işlev görebilir. ${ }^{16,17}$

PDMS'ler, özellikle, kullanım tarafına bağlı olarak Candida, Streptococcus, Staphylococcus veya Pseudomonas türlerinin kolonizasyonuna yatkındır. Ağız ortamında, Candida türlerinin astar materyallerde daha yaygın kolonize olduğu bildirilmiştir. ${ }^{12}$ Candida albicans'in yumuşak astar materyallerine ilişkin patogenezisinde enfeksiyon oluşumunun ilk safhası yüzeye adezyonudur; ardından kolonizasyon, proliferasyon ve biyofilm oluşumu gelişir. ${ }^{18,19}$ Candida albicans'in yüzeye adezyonu, spesifik ve non-spesifik adezyon mekanizmaları ile oluşmaktadır. Adezyonda etkili non-spesifik faktörler, yüzey ve mikroorganizma arasındaki hidrofobik çekim ve elektrostatik kuvvetlerdir. Bu faktörler mikroorganizma ve yüzey arasında spesifik adezyon için gerekli yakınlaşmayı sağlarlar ve böylece spesifik adezinler ile konak reseptör arasında bağlantı sağlanır. Bu safha mikroorganizmaların yüzeye sıkı bağlantısı için gereklidir ve bundan sonra filamentöz genişleme ile mantarın proliferasyonu ve biyofilm oluşmaktadır. ${ }^{19,20}$ Tükürük, ağız ortamı ve yüzey topografisi bu karmaşık süreci etkileyebilir. Candida hücreleri katı yüzeylerdeki küçük kaviteler ve düzensizliklerde birikmeye ve kümeler oluşturmaya eğilimlidir. ${ }^{12}$

Yüzey topografisindeki farklılıkların $C$. albicans'in yüzeye tutunmasını etkilediği, pürüzlü ve hidrofobik yüzeylerde Candida adezyonunun fazla olduğu pek çok çalışmada gösterilmiştir. ${ }^{16,21}$ Farklı içerikli ısı ve oda ısı- sında polimerize olabilen silikon esaslı yumuşak astar materyallerinin farklı yüzey özelliklerinden dolayı C. albicans adezyonları ve sonrasında gelişen biyofilm formasyonları açısından aralarında farklılık olabileceği belirtilmiştir. ${ }^{22}$ Önceki çalışmaların çoğunda $C$. albicans bağlanması klinik durumu yansıtmayan düz yüzeyli yumuşak astar materyalleri üzerinde değerlendirilmiştir ${ }^{12,16,23,24} \mathrm{Bu}$ çalışmanın amacı, düz ve pürüzlü yüzeylerin silikon esaslı farklı yumuşak astar materyallerde $C$. albicans biyofilm oluşturma etkisini karşılaştırmak ve aynı zamanda bu durumun materyal hidrofobisitesi ile ilişkisini incelemektir.

\section{Gereç Ve Yöntem}

Bu çalışmada, ikisi ısı ile polimerize olan (Molloplast B; polidimetilsiloksan, Detax $\mathrm{GmbH}$, Ettlingen, Almanya ve Permaflex; polidimetilsiloksan, Kohler, Medizintechnik, Danningen, Almanya) ve ikisi oda Isısında polimerize olan (Elitesoft; polivinilsiloksan, Elite Soft Relining, Kettenbach, Almanya ve Ufi Gel P; modifiye polidimetilsiloksan, Voco, Cuxhaven, Almanya) dört farklı silikon esaslı yumuşak astar materyali test edildi. Her bir yumuşak astar materyali için test örnekleri düz ve pürüzlü yüzey yapısı elde etmek üzere iki farklı yüzeye karşı hazırlandı $(n=5)$.

Düz yüzeyli yapı için, örnekler muflada iki cam tabaka arasında hazırlandı; bunun için $5 \times 5 \times 2 \mathrm{~mm}$ boyutlarında iki cam tabaka ve aynı boyutta bir pembe modelaj mumundan yararlanıldı. Öncelikle alt mufla içerisine alçı döküldü ve üzerine alçıya gömülecek şekilde ilk cam tabaka yerleştirildi. Alçı sertleştikten sonra bu cam yüzey üzerine pembe mum kalıp dikkatlice yerleştirildi ve üzerine ikinci cam tabaka yerleştirildi. Daha sonra cam dışında kalan alçı yüzeyler yalıtılarak üst mufla kapağı kapatılıp alçı döküldü. Muflalama sonrası geleneksel şekilde mum eritilerek uzaklaştırıldı ve iki cam tabaka arasında kalan boşluğa yumuşak astar materyali yerleştirildi. Molloplast $\mathrm{B}$ ve Permaflex materyalleri 2 saat süreyle $100{ }^{\circ} \mathrm{C}$ su banyosunda polimerize edilirken, Elite Soft ve Ufi Gel P materyalleri $40-45^{\circ} \mathrm{C}$ 'lik basınçlı su banyosunda sırasıyla 10 ve $15 \mathrm{dk}$ süreyle polimerize edildiler.

Düzensiz yapıya sahip oral mukozayı taklit etmesi amacıyla, diğer örnek grupları doğrudan alçı üzerinde geleneksel yolla hazırlandı. Alt mufla alçısı tam sertleşmeden, önceden belirtilen boyutlardaki mum kalıplar alçı içine gömüldü. Sertleşen alçı yüzeyler yalıtıldıktan sonra, üst mufla parçası yerleştirilerek daha önce belirtildiği şekilde muflalama işlemi ve her bir materyalin polimerizasyonu sağlandı. Böylece, her bir materyal için test edilen her iki yüzey yapısına sahip 5'er örnek olmak üzere toplam 40 örnek elde edildi.

Tüm örnekler aynı araştırıcı tarafından hazırlandı. Yüzey pürüzlülüğü ve temas açısı ölçümü öncesinde örnekler kuru ortamda oda ısısında $\left(23 \pm 1^{\circ} \mathrm{C}\right) 24$ saat bekletildi. 


\section{Yüzey pürüzlülüğü ölçümü}

Hazırlanan örneklerin yüzey pürüzlülükleri profilometre cihazı ile ölçüldü. (Perthometer M2, Mahr Gmbh, Göttingen, Almanya). Test koşulları, elmas uç çapı $5 \mu \mathrm{m}$ ve uç hızı $0.25 \mathrm{~mm} / \mathrm{sn}$ olarak belirlendi. Profilometrenin ucu, örnek yüzeyinin bir ucundan diğer ucuna bir çizgi doğrultusunda getirilerek ortalama Ra değeri $\mu \mathrm{m}$ birimiyle hesaplandı. Bu ölçümler örnek yüzeylerinin iki farklı alanında üç kez tekrarlandı ve değerlerin ortalaması alınarak her bir örneğin yüzey pürüzlülüğü hesaplandı.

\section{Temas açısı ölçümü}

Test edilen materyallerin hidrofobisitelerini değerlendirmek için temas açıları ölçüldü. Bunun için Sesil Damla Şekli Analiz Sistemi (Sessile Drop Shape Analysis, DSA 100, Kruess, Almanya) kullanıldı. Örneklerin üzerine 20 $\mu \mathrm{L}$ distile su damlası damlatıldı. Temas açısı, damlanın konturu ile yüzeyin projeksiyonunun kesiştiği noktadaki açı olarak ölçüldü. Her bir örnek için 3 ölçüm yapılarak ortalama değer kaydedildi.

\section{Mikrobiyolojik değerlendirme}

Mikrobiyolojik değerlendirme öncesi tüm örnekler, otoklavda $121^{\circ} \mathrm{C}$ ve 1.2 bar basınç altında $18 \mathrm{dk}$ süreyle steril edildi.

Yumuşak astar materyalleri, biyofilm oluşturma kapasitesinin değerlendirilmesinde, klinik örneklerin tanımlanmasında referans köken olarak kullanılan C. albicans ATCC 10231 kullanıldı (Hacettepe Üniversitesi Biyoloji Bölümü, Biyoteknoloji Anabilim Dalı Laboratuvarı, Ankara, Türkiye). Candida albicans ATCC 10231'in stok kültüründen alınan inokülat, Sabouraud Dextrose Broth (SDB; Difco, Detroit, MI, ABD) $37^{\circ} \mathrm{C}$ 'de 24 saat enkübe edildi. Yumuşak astar materyalleri steril koşullar altında 24 kuyucuklu polistren plakların her bir kuyucuğuna bırakıldı ve üzerine $800 \mu$ l taze SDB eklendi. Hazırlanmış olan C. albicans ATCC 10231 kültüründen her bir kuyucuğa $200 \mu$ inokülasyon yapılarak örnekler $37^{\circ} \mathrm{C}$ 'de 48 saat çalkalanarak enkübe edildi.

\section{Biyofilm oluşumunun spektrofotometrik ölçülmesi}

Enkübasyonun ardından kültür ortamı otomatik pipet yardımıyla uzaklaştırıldı. Steril koşullar altında, örnekler ye- niden 24 kuyucuklu polistren plaklara aktarılarak $1 \mathrm{~mL}$ fosfat-tamponlu salin solüsyonu ile 3 defa yıkandı ve oda sıcaklığında kurutma sağlandı. Kurutma işlemi tamamlandıktan sonra \%0.1 kristal viyole solüsyonu (Sigma Aldrich, St. Louis, MO, ABD) ile boyanarak, kuyucuk içerisindeki örnekler 10-15 dk oda sıcaklığında bırakıldı. Boya 3-4 defa su ile yıkanarak uzaklaştırılı. Örnekler 65 'C'de 2 saat kurumaya bırakılarak yüzeyde oluşan biyofilmin sabitlenmesi sağlandı. Boya, $1 \mathrm{~mL} \% 30$ asetik asit çözeltisi ile çözülerek 492 nm'de spektrofotometrik (Elisa Reader, ER 2005, Equipar, italya) olarak okundu.

\section{İstatistiksel değerlendirme}

Yumuşak astar maddelerinin yüzey pürüzlülüğü, biyofilm formasyonu ve temas açıları açısından birbiri ile karşılaştırılması one-way Anova ve post-hoc Tukey testi ile yapıldı. Cam veya alçı yüzeye karşı hazırlanan her bir yumuşak astar maddesinin $C$. albicans tutulumu ile yüzey özellikleri arasındaki ilişki Pearson korelasyon analizi ile karşılaşıııılı. Sonuçlar $p<0.05$ için istatistiksel olarak anlamlı kabul edildi.

\section{BULGULAR}

Test edilen materyallerin yüzey pürüzlülük ve temas açısı değerleri ile biyofilm formasyonu minimum, maksimum ve ortalama değerleri Tablo 1'de verildi. Test edilen materyallerin istatistiksel karşılaşııma bulguları Tablo 2'de belirtildi. Alçı yüzeye karşı hazırlanan tüm yumuşak astar materyallerinde, yüzey pürüzlülüğü, temas açısı değerleri ve biyofilm formasyonu cam üzerinde hazırlananlara göre istatistiksel olarak daha fazla bulundu $(p<0.05)$.

Alçı üzerinde hazırlanan örneklerde en fazla yüzey pürüzlülüğü $(\mathrm{Ra})$, Molloplast B'de bulundu (3.31 \pm 0.24$)$, ve bu değer Permafleks dışındaki materyallerin yüzey pürüzlülüğünden istatistiksel olarak farklıydı. En düşük yüzey pürüzlülüğü değeri ise diğer materyallerin hepsinden istatistiksel olarak farklı olarak Ufi Gel P'de bulundu (2.24 \pm 0.27$)$. Cam üzerinde hazırlanan örneklerde ise en fazla yüzey pürüzlülüğünü istatistiksel anlamlı olarak Ufi Gel P gösterirken (1.10 \pm 0.28$)$; en az yüzey pürüzlülüğünü Permaflex $(0.58 \pm 0.14)$ gösterdi, ancak bu değer sadece Ufi Gel P'den istatistiksel olarak farklı bulundu.

Tablo 1. Yumuşak astar materyallerinin yüzey pürüzlülüğü, temas açısı ve biyofilm formasyonu değerlerinin maksimum, minimum ve ortalama değerleri

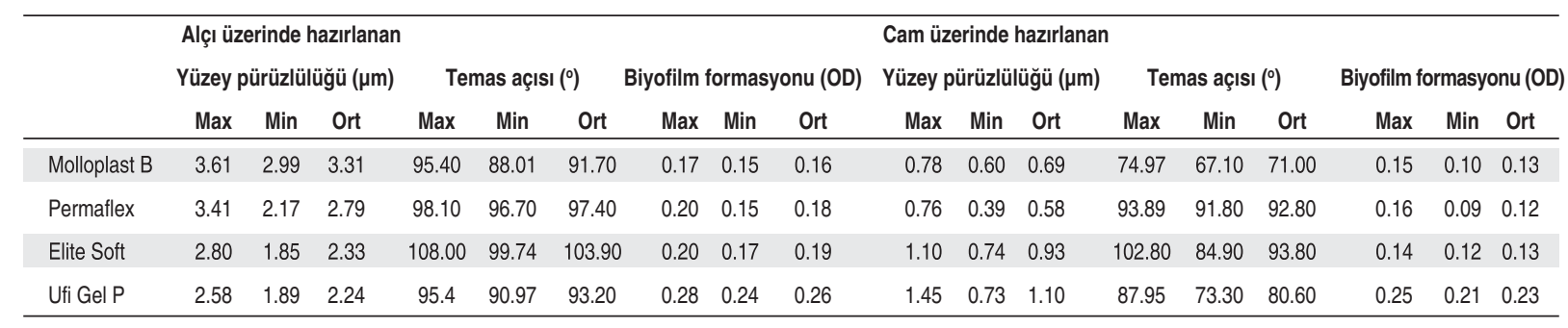


Tablo 2. Yumuşak astar materyallerinin yüzey pürüzlülüğü, temas açısı ve biyofilm formasyonu değerlerinin ortalama ve standart deviasyonları $(n=5)$

\begin{tabular}{|c|c|c|c|c|c|c|}
\hline & \multicolumn{3}{|l|}{ Alçı üzerinde hazırlanan } & \multicolumn{3}{|l|}{ Cam üzerinde hazırlanan } \\
\hline & Yüzey pürüzlülüğü $(\mu \mathrm{m})$ & Temas açısı $\left({ }^{\circ}\right)$ & Biyofilm formasyonu (OD) & Yüzey pürüzlülüğü ( $\mu$ m) & Temas açısı $\left({ }^{\circ}\right)$ & Biyofilm formasyonu (OD) \\
\hline Molloplast-B & $3.31 \pm 0.24^{a, b, A}$ & $91.70 \pm 2.90^{c, d, E}$ & $0.16 \pm 0.01^{g, 1}$ & $0.69 \pm 0.07, \mathrm{~A}$ & $71.00 \pm 3.16^{1, \mathrm{~m}, \mathrm{n}, \mathrm{E}}$ & $0.13 \pm 0.02^{r, l}$ \\
\hline Permaflex & $2.79 \pm 0.49^{B}$ & $97.40 \pm 0.54^{c, e, F}$ & $0.18 \pm 0.02^{h, J}$ & $0.58 \pm 0.14^{\mathrm{j}, \mathrm{k}, \mathrm{B}}$ & $92.80 \pm 0.83^{1,0, F}$ & $0.12 \pm 0.03^{\mathrm{s}, J}$ \\
\hline Elite Soft & $2.33 \pm 0.38^{a, c}$ & $103.90 \pm 3.39^{\mathrm{d}, \mathrm{e}, \mathrm{f}, \mathrm{G}}$ & $0.19 \pm 0.01^{1, k}$ & $0.93 \pm 0.14^{\mathrm{i}, \mathrm{C}}$ & $93.80 \pm 7.20^{m, p, G}$ & $0.13 \pm 0.01^{\mathrm{t}, \mathrm{K}}$ \\
\hline Ufi Gel P & $2.24 \pm 0.27^{\mathrm{b}, \mathrm{D}}$ & $93.20 \pm 1.78^{\mathrm{f,H}}$ & $0.26 \pm 0.02^{h, g, l, L}$ & $1.10 \pm 0.28^{\mathrm{i}, \mathrm{k}, \mathrm{D}}$ & $80.60 \pm 5.90^{n, 0, p, H}$ & $0.23 \pm 0.02^{r, s, t, L}$ \\
\hline
\end{tabular}

Satır üzerinde istatistiksel anlamlı farkııık gösteren değerler aynı üstsimge küçük harfler ile belirtilmiştir. Sutunlar içerisinde istatistiksel farklıık gösteren değerler aynı üstsimge büyük harfler ile belirtilmiştir. Veriler ortalama \pm standart deviasyon olarak sunulmuştur, İstatistiksel anlamlı farklılık $p<0.05$ olarak belirlenmiştir

Hem alçı hem de cam yüzeyde hazırlanan örneklerde en yüksek temas açısı Elite Soft'ta bulundu (sırasıyla $103.90 \pm 3.39$ ve $93.80 \pm 7.20 ; p<0.05)$. Bu değer alçı yüzeylerde tüm materyallerden istatistiksel olarak anlamlı bir farklılık gösterirken, cam yüzeylerde Permafleks dışında hepsinde istatistiksel farklılık gösterdi. En düşük temas açısı Molloplast B'de gözlendi $(91.70 \pm 2.90$ ve 71.00ะ3.16); alçı yüzeyde Ufi Gel P dışındakilerin hepsinden istatistiksel olarak farklı iken, cam yüzeylerde diğer yumuşak astar materyallerinin tümünden istatistiksel olarak anlamlı farklılık göstermiştir.

Alçı ve cam yüzeyde hazırlanan yumuşak astar materyalleri biyofilm formasyonu açısından karşılaştırıldığında her iki yüzeyde de en fazla $C$. albicans biyofilm oluşumu Ufi Gel P'de bulundu (alçı yüzeyde $0.26 \pm 0.02$ ve cam yüzeyde $0.23 \pm 0.02$ ); bu değerler istatistiksel olarak aynı koşullarda hazırlanan diğer yumuşak astar materyallerinkinden farklılık gösterdi $(p<0.05)$. Diğer yumuşak astar maddelerinde $C$. albicans değerleri birbirine yakın değerlerde olup aralarında istatistiksel farklılık bulunmadı ( $p>0.05)$.

Pearson korelasyon analizi sonucunda, C. albicans tutulumu ile hiçbir yumuşak astar materyalinin yüzey özellikleri (yüzey pürüzlülüğü ve temas açısı) arasında korelasyon bulunmadı (Tablo 3; $p>0.05$ ).

\section{TARTIŞMA}

Yumuşak astar materyallerin değerlendirilmesi genel olarak reziliens, yırtılma direnci, biyouyum, yeterli bağlantı dayanımı, renk stabilitesi ve abrazyona direnç gibi özelliklere dayalı olarak yapılmıştır. ${ }^{11,15,25}$ Bazı materyal tiplerinin, bu özellikleri diğerlerinden daha uzun süre koruduğu bildirilmişse de protez kaide polimerlerine bağlantı kaybı ve yumuşak astarlarda mantar kolonizasyonu, kullanımlarını sınırlayan önemli bir sorun olmaya devam etmektedir. ${ }^{11,15,25}$

Çalışmaların pek çoğunda yumuşak astar materyal test örnekleri, standardizasyonu sağlamak amacıyla cam yüzeyler üzerinde hazırlanmıştır, 13,16,23,24 ancak bu durum klinik koşulları doğru yansıtmaktan uzaktır, çünkü özellikle üst tam protezin iç yüzeyi olmak üzere mukozal yapı düzensizlik gösterir. Bu nedenle çalışmamızda yumuşak astar örnekler standardizasyon amacıyla hem cam, hem de protez doku yüzeyindeki pürüzlülük etkisini yansıtması için alçı yüzeylere karşı hazırlandı.

Yumuşak astar materyallerde kolonizasyon, öncelikle mikroorganizmaların adezyonu ile başlar. Hücre bölünmesi ve bağlanma ile biyofilm ve/veya plak oluşumunda yüzey pürüzlülüğü önemli bir etkendir. ${ }^{26}$ Morgan \& Wilson ${ }^{27}$ pürüzlü akrilik rezinlere bakteri ve mantar afinitesi olduğunu göstermişler; Veran \& Maryan ${ }^{28}$ cam üzerinde hazırlanan ısı ve oda ısısında sertleşen silikon esaslı yumuşak astar materyallerinde alçı üzerinde hazırlananlara göre daha az Candida tutulumu olduğunu bildirmişlerdir. Çalışmamızda, tüm yumuşak astar materyalleri, alçı yüzeye karşı hazırlandığında cam yüzeye karşı hazırlananlardan anlamlı şekilde yüksek değerde temas açısı ve yüzey pürüzlülük değerleri gösterdi. Pürüzlü ve temas açısının fazla olduğu yüzeylerde $C$. albicans tutulumunun da fazla olacağını bildi-

Tablo 3. Candida albicans biyofilm formasyonu ile temas açısı ve yüzey pürüzlülüğü arasındaki korelasyon

\begin{tabular}{|c|c|c|c|c|c|c|c|c|}
\hline & \multicolumn{4}{|c|}{ Yüzey pürüzlülüğü ( $\mu$ m) } & \multicolumn{4}{|c|}{ Temas açısı $\left({ }^{\circ}\right)$} \\
\hline & \multicolumn{2}{|l|}{ Alçı } & \multicolumn{2}{|l|}{ Cam } & \multicolumn{2}{|l|}{ Alçı } & \multicolumn{2}{|l|}{ Cam } \\
\hline & $p$ & $r$ & $p$ & $r$ & $p$ & $r$ & $\mathbf{P}$ & $r$ \\
\hline Molloplast B & 0.27 & 0.60 & 0.49 & -0.40 & 0.94 & -0.47 & 0.77 & 0.18 \\
\hline Permaflex & 0.70 & -0.83 & 0.18 & 0.70 & 0.42 & -0.46 & 0.61 & 0.30 \\
\hline Elite Soft & 0.21 & 0.66 & 0.10 & 0.10 & 0.05 & 0.80 & 0.17 & 0.72 \\
\hline Ufi Gel P & 0.52 & -0.38 & 0.26 & 0.62 & 0.23 & 0.64 & 0.58 & 0.33 \\
\hline
\end{tabular}

istatistiksel anlamlıık değeri p<0.05 kabul edilmiştir; $r$ : Pearson korelasyon katsayısı; Pearson korelasyon analizi 
ren önceki çalışma bulgularına ${ }^{29,30}$ paralel olarak, çalışmamızda da alçı yüzeylere karşı hazırlanan tüm yumuşak astar materyallerde cama karşı hazırlananlardan istatistiksel olarak daha fazla $C$. albicans biyofilmi oluştuğu saptandı. Buna karşın örneklerin yüzey pürüzlülüğü ve temas açısı değerleri ile biyofilm formasyonu açısından korelasyon bulunamamıştır. Yüzey yapısındaki pürüzlülüklerin daha geniş yüzey alanı ve daha korunmalı çevre sağlayarak kolonizasyona zemin hazırladığı söylenebilir.

Isı ile polimerize olan yumuşak astar materyallerinin çapraz bağ yapısının daha fazla olmasından dolayı daha sert ve düz yüzeylere sahip olabileceği belirtilmiştir. ${ }^{21,23}$ Çalışmamızda, cama karşı hazırlandıklarında Molloplast $B$ ve Permaflex örnekleri, oda ısısında polimerize edilen tipteki Ufi Gel P ve Elite-Soft örneklerine göre genel olarak daha düşük yüzey pürüzlülügü gösterirken, alçı yüzeye karşı hazırlandıklarında daha yüksek yüzey pürüzlülügü gözlendi. Bu bulgu, kullanılan materyaller farklı olsa da aynı yöntemle ısı ile ve oda ısısında polimerize materyallerin yüzey pürüzlülüğünün test edildiği Nevzatoğlu ve arkadaşlarının ${ }^{21}$ sonuçlarıyla uyumludur. Keza, cama karşı hazırlananlarla ilgili sonuç, benzer yöntem kullanan Tari ve arkadaşlarının ${ }^{31}$ çalışma bulgularıyla örtüşmektedir. Isı ile polimerize yumuşak astarların alçı yüzeyde daha yüksek pürüzlülük göstermesi, polimerizasyon sırasında sıcaklıkla birlikte viskozitelerinin artarak andırkatlara penetre olmasından kaynaklanabilir.

Kang ve ark. ${ }^{22}$ benzer içeriğe sahip farklı yumuşak astar materyallerinin farklı hidrofobisite gösterdiklerine işaret etmiştir. Çalışmamızda, temas açısı değerleri yönünden, hem cam hem de alçı yüzeyde hazırlanan tüm örnekler arasında en düşük temas açısı Molloplast B'de, en yüksek Elite Soft'ta saptandı. Benzer yapıya sahip olan yumuşak astar materyallerinde farklı yüzey pürüzlülüğü ve hidrofobisite göstermesinin materyallerin içeriklerinden kaynaklanabileceği bildirilmiştir. Çalışmamızda kullanılan tüm materyallerde ana bileşen polidimetilsiloksan olsa da materyaller, üreticiler tarafından tam olarak belirtilmeyen farklı yapı ve yüzdelerde katalist, çapraz bağlayıcı ve doldurucu gibi diğer bileşenlerden oluşmaktadırlar.

Pearson korelasyon analizi, test edilen yumuşak astar materyallerinin temas açıları ve yüzey pürüzlülüğü değerleri ile $C$. albicans biyofilm formasyonları arasında doğrusal bir ilişki göstermedi. Hem cam hem alçı yüzeylerde hazırlanan yumuşak astar materyallerde en fazla biyofilm formasyonu oda Isısında polimerize edilen Ufi Gel P'de bulundu. Bu sonuç, kısmen içeriğindeki ana bileşenin diğerlerinden farklı olarak modifiye PDMS oluşuna bağlanabilir. Ancak daha önemlisi, biyofilm oluşumu sırasında ortam $\mathrm{pH}$ değerlerinin yumuşak astar materyal yapısına bağlı olarak değişkenlik göstermesidir. Mikrobiyal kolonizasyon sırasında hücreler doğal metobolizma ürünü olarak asidik maddeler üretmektedirler ve bu durumun örnek yüzeyinin $\mathrm{pH}$ değerini etkilediği bildirilmiştir. ${ }^{23}$ Çalışmamızda, her ne kadar test parametresi olarak incelenmemiş olsa da, Ufi Gel P'deki daha yüksek $C$. albicans biyofilm formasyonu, C. albicans'ın materyal yüzeyinde oluşturduğu yüksek ph değerinden kaynaklı olabilir. Öte yandan en düşük biofilm formasyonu Molloplast B'de görüldü. Daha önce yapılan bir çalışmada, Molloplast B'nin mikroorganizma kolonizasyonunu inhibe ettiği bildirilirken, ${ }^{32}$ diğer bir çalışma mikrobiyal kolonizasyon oluşturduğuna işaret etmektedir. ${ }^{16} \mathrm{Bu}$ farklı sonuçlar polimerize olmamış Molloplast B'nin içindeki aktif maddenin (metakriloyloksipropiltrimetoksisilan) mikroorganizma kolonizasyonun inhibe edebileceği ${ }^{33-35}$ ancak polimerize olduktan sonra bu maddenin inaktif olarak Molloplast B'nin inhibe edici etkisinin görülmediği şeklinde açıklanmaktadır. Daha sonra, polimerize olmuş Molloplast B kullanılarak yapılan, Burns ve ark. ${ }^{26}$ ile Bulad ve ark. ${ }^{33}$ çalışmalarında Molloplast B'nin Candida biyofilm formasyonunu inhibe edici etkisi görülmemiştir.

\section{SonUç}

Farklı bileşen içeren, ısı ve oda ısısında polimerize olan silikon esaslı yumuşak astar materyallerinin, yüzey pürüzlülüğü ve temas açısı ile belirlenen yüzey özellikleri ve $C$. albicans biyofilm oluşumu arasında ilişki görülmedi. Ancak, her iki yüzey karakteristiğinde de en fazla biyofilm formasyonu oluşturan Ufi Gel P'nin klinikte diğer yumuşak astar materyallerine göre daha sık yenilenmesi önerilebilir. Ayrıca, yumuşak astar materyallerinin düzgün yüzeyli olarak hazırlanması da $C$. albicans biyofilm oluşumunu önlemede etkili olabilir.

Çıkar çatışması: Yazarlar bu çalışmayla ilgili herhangi bir çıkar çatışmalarının bulunmadığını bildirmişlerdir.

\section{TEŞEKKÜR VE ANMA}

Bu çalışma TDB 20. Uluslararası Diş Hekimliği Kongresi'nde bildiri olarak sunulmuştur (29-31 Mayıs 2014, Kuşadası, Aydın, Türkiye).

\section{KAYNAKLAR}

1. Turgut M, Bolayır G, Doğan OM, Keskin S, Doğan A, Boztuğ A. Bond strength of a silicone soft lining material to poly(methyl methacrylate) resin treated with maleic anhydride and its terpolymers. J Adhes 2007;83:927-38.

2. Sinobad D, Murphy WM, Huggett R, Brooks S. Bond strength and rupture properties of some soft denture liners. J Oral Rehabil 1992;19:151-60.

3. Karacaer Ö, Karaarslan A, Dogan A, Özenci H. Yumuşak astar materyallerinin Candida albicans üzerine etkilerinin değerlendirilmesi. GÜ Diş Hek Fak Der 1994;2:103-7.

4. Doğan OM. Yumuşak astar materyallerin klinik endikasyonları. Atatürk Üniv Diş Hek Fak Derg 2005;15:70-5.

5. Braden M, Wright PS, Parker S. Soft lining materials--a review. Eur J Prosthodont Restor Dent 1995;3:163-74.

6. Bal BT, Yavuzyılmaz H. Yumuşak astar maddeleri. Atatürk Üniv Diş Hek Fak Derg 2006;Suppl 1:53-60. 
7. Soygun K, Bolayır G, Dogan A, Demir H, Dogan M, Keskin S. Effect of surface treatments on tensile bond strength between a silicone soft liner and heat-cured denture base resin. J Adhes 2011;87:951-65.

8. Anusavice KJ. Phillips' science of dental materials. 10th edn. Philadelphia: WB Sanders;1995.

9. Demir H, Soygun K, Dogan A, Keskin S, Dogan OM, Bolayir G. Effect of maleic anhydride pretreatment on tensile bond strength of a silicone soft liner to a denture base polymer. J Adhes Dent 2011;13:481-7.

10. Noort R. Introduction to dental materials, 2nd edn. St. Louis: Mosby Elsevier; 2002.

11. Roth J, Albrecht V, Nitschke M, Bellmann C, Simon F, Zschoche S, et al. Surface functionalization of silicone rubber for permanent adhesion improvement. Langmuir 2008;24:12603-11.

12. Mutluay MM, Oğuz S, Ørstavik D, Fløystrand F, Doğan A, Söderling $E$, et al. Experiments on in vivo biofilm formation and in vitro adhesion of Candida species on polysiloxane liners. Gerodontology 2010;27:283-91.

13. Busscher $\mathrm{HJ}$, van der Mei HC. Physico-chemical interactions in initial microbial adhesion and relevance for biofilm formation. Adv Dent Res 1997;11:24-32.

14. Yerliyurt K, Nalbant D, Kalkancı A, Kuştimur S. İki farklı silikon esaslı yumuşak astar maddesinin zamana bağlı olarak yüzeylerinden izole edilen C. albicans hücrelerinde ALS1 adezyon geninin ekspresyonundaki değişimin incelenmesi. Gaziosmanpaşa Üniversitesi Tıp Fakültesi Dergisi 2012;4:9-21.

15. Garcia LT, Jones JD. Soft liners. Dent Clin North Am 2004;48:70920, vii.

16. Nikawa H, Jin C, Makihira S, Egusa H, Hamada T, Kumagai H. Biofilm formation of Candida albicans on the surfaces of deteriorated soft denture lining materials caused by denture cleansers in vitro. J Oral Rehabil 2003;30:243-50.

17. Puius YA, Scully B. Treatment of Candida albicans pericarditis in a heart transplant patient. Transpl Infect Dis 2007;9:229-32.

18. Boscato N, Radavelli A, Faccio D, Loguercio AD. Biofilm formation of Candida albicans on the surface of a soft denture-lining material. Gerodontology 2009;26:210-3.

19. Williams DW, Kuriyama T, Silva S, Malic S, Lewis MA. Candida biofilms and oral candidosis: treatment and prevention. Periodontol 2000 2011;55:250-65.

20. Waters MG, Williams DW, Jagger RG, Lewis MA. Adherence of Candida albicans to experimental denture soft lining materials. J Prosthet Dent 1997;77:306-12.

21. Nevzatoğlu EU, Ozcan M, Kulak-Ozkan Y, Kadir T. Adherence of Candida albicans to denture base acrylics and silicone-based resilient liner materials with different surface finishes. Clin Oral Investig 2007;11:231-6.

22. Kang SH, Lee HJ, Hong SH, Kim KH, Kwon TY. Influence of surface characteristics on the adhesion of Candida albicans to various denture lining materials. Acta Odontol Scand 2013;71:241-8.

23. Vural C, Ozdemir G, Kurtulmus H, Kumbuloglu O, Ozcan M. Comparative effects of two different artificial body fluids on Candida albicans adhesion to soft lining materials. Dent Mater J 2010;29:206-12.

24. Hahnel S, Rosentritt M, Bürgers R, Handel G, Lang R. Candida albicans biofilm formation on soft denture liners and efficacy of cleaning protocols. Gerodontology 2012;29:e383-91.

25. Mutluay MM, Oguz S, Fløystrand F, Saxegaard E, Dogan A, Bek B, et al. A prospective study on the clinical performance of polysiloxane soft liners: one-year results. Dent Mater J 2008;27:440-7.

26. Burns DR, Burns DA, DiPietro GJ, Gregory RL. Response of processed resilient denture liners to Candida albicans. J Prosthet Dent 1987;57:507-12.

27. Morgan TD, Wilson $M$. The effects of surface roughness and type of denture acrylic on biofilm formation by Streptococcus oralis in a constant depth film fermentor. J Appl Microbiol 2001;91:47-53.

28. Verran J, Maryan CJ. Retention of Candida albicans on acrylic resin and silicone of different surface topography. J Prosthet Dent 1997;77:535-9.
29. Yamauchi M, Yamamoto K, Wakabayashi M, Kawano J. In vitro adherence of microorganisms to denture base resin with different surface texture. Dent Mater J 1990;9:19-24.

30. Pereira-Cenci T, Cury AA, Cenci MS, Rodrigues-Garcia RC. In vitro Candida colonization on acrylic resins and denture liners: influence of surface free energy, roughness, saliva, and adhering bacteria. Int $\mathrm{J}$ Prosthodont 2007;20:308-10.

31. Tari BF, Nalbant D, Dogruman AI F, Kustimur S. Surface roughness and adherence of Candida albicans on soft lining materials as influenced by accelerated aging. J Contemp Dent Pract 2007;8:18-25.

32. Nikawa $H$, Jin $C$, Hamada $T$, Murata $H$. Interactions between thermal cycled resilient denture lining materials, salivary and serum pellicles and Candida albicans in vitro. Part I. Effects on fungal growth. J Oral Rehabil 2000;27:41-51.

33. Taylor RL, Bulad K, Verran J, McCord JF. Colonization and deterioration of soft denture lining materials in vivo. Eur J Prosthodont Restor Dent 2008;16:50-5.

34. Wright PS. The effect of soft lining materials on the growth of Candida albicans. J Dent 1980;8:144-51.

35. Pavan S, dos Santos PH, Filho JN, Spolidorio DM. Colonisation of soft lining materials by micro-organisms. Gerodontology 2010;27:211-6.

\section{Evaluation of Candida albicans biofilm formation on different soft lining materials}

\section{Abstract}

OвJECTIVE: The purpose of this study was to evaluate Candida albicans biofilm formation on soft liners prepared against two surfaces with different properties.

Materials and Method: Four soft liners (Molloplast B, Permafleks, Elite-soft, Ufi Gel P) were prepared against glass or dental plaster surfaces $(5 \times 5 \times 2 \mathrm{~mm} ; \mathrm{n}=5)$. The surface roughness and contact angle of the soft liner specimens were measured. Candida albicans ATCC 10231 was grown in Sabouraud dextrose broth (SDB) at $37^{\circ} \mathrm{C}$ for $24 \mathrm{~h}$. For biofilm formation, the specimens were incubated in polystrene wells together with fresh SDB and the $C$. albicans culture at $37^{\circ} \mathrm{C}$ for $48 \mathrm{~h}$. The specimens were stained with $0.1 \%$ crystal violet and dehydrated at $65{ }^{\circ} \mathrm{C}$. The quantification of the $C$. albicans biofilm formation was performed spectrophotometrically. Comparison of the surface roughness, contact angle and biofilm formation between the materials was done using one way ANOVA and Tukey tests. Correlation between surface roughness, contact angle and biofilm formation on the specimens prepared against glass or plaster surfaces was performed using Pearson correlation analysis.

RESULTS: Specimens prepared against plaster showed significantly higher surface roughness, contact angle and biofilm formation values in comparison to those prepared against glass surface $(p<0.05)$. Among the specimens prepared against the dental plaster surface, the highest and the lowest biofilm formation values were observed in the 
Ufi Gel P and Molloplast B specimens, respectively. Among the specimens prepared against the glass surface, the greatest biofilm formation was shown for Ufi Gel P. There was no correlation between the surface properties (surface roughness and contact angle) and the amount of biofilm formation for the soft liner materials tested in this study $(p>0.05)$.
Conclusion: Although the soft liners tested in this study had similar surface topographic properties, they showed different amounts of $\boldsymbol{C}$. albicans biofilm formation. Smooth surfaces were found to reduce the biofilm formation.

KEYwoRDS: Biofilm; Candida albicans; polydimethylsiloxanes 